\title{
Numerical and Experimental Analysis of Horizontal Stress Changes and Soil Collapse During Chemical Dissolution in a Modified Oedometer Cell
}

\author{
C. Lins, N. Silva, L. Guimarães, A. Lima, I. Gomes
}

\begin{abstract}
The purpose of this paper is to investigate the horizontal stress evolution and soil collapse during the cement dissolution process using a combination of experimental and numerical methods. The experimental procedure was carried out using a modified oedometer cell with horizontal stress measurements and synthetic samples in order to simulate simultaneous cement dissolution, stress changes and sample deformation. The samples were loaded at a constant vertical stress and exposed to a reactive fluid which dissolved the cementation of the artificial soil. During the dissolution process, sample volume decreased and horizontal stress changes were observed. Initially the horizontal stress decreased due to grain mass loss and then increased due to solid matrix rearrangement. Numerical simulation of these coupled chemical and mechanical processes was performed using a general purpose finite element code capable of performing numerical analysis of engineering problems. The constitutive model adopted to reproduce the soil behavior is an extension of the Barcelona Basic Model for unsaturated soils including the cement mineral concentration as state variable. Some new features were incorporated to the original elasto-plastic model in order to represent the results observed in the experiments. In this paper a good agreement between experimental and numerical results was achieved.
\end{abstract}

Keywords: modified oedometer cell, soil collapse, horizontal stress changes, chemical dissolution, coupled simulation, elasto-plastic model.

\section{Introduction}

The recent development of experimental techniques, where measurements of variables of different nature (thermal, hydraulic, mechanical and chemical) can be performed simultaneously in the same experiment, allowed the incorporation of new variables and equations to the numerical procedures used to reproduce the behavior of soils and rocks. In geotechnical engineering, such models are mainly related to the effects of partial saturation and consequences of chemical actions on the porous media, where suctions (matric and osmotic) and chemical concentrations were included as state variables of the mechanical problem (Alonso et al., 1990; Castellanza \& Nova, 2004; Gens \& Nova, 1993; Guimarães et al., 2013).

Some geotechnical problems that are likely to require new approaches or, at least, extension of the classical ones are as follows: collapse and swelling of active soils, subsidence due to oil and gas extraction, dissolution, degradation and weathering of soils and rocks and $\mathrm{CO}_{2}$ sequestration (Gens, 2010).

For instance, the large-scale injection of $\mathrm{CO}_{2}$ and other gases into geological formations may induce complex interaction of multiphase flow, diffusion, convection, mineral and gas dissolution, mineral precipitation, and other chemical reactions. Depending on the composition of the rock and fluids and $\mathrm{CO}_{2}$ injection strategy, the rock-fluid interactions may have a significant impact on safety and reservoir storage capacity (Lins, 2012).

The injection and extraction of fluids cause mineral dissolution, changes of pressure, temperature and saturation that affect the state of stress resulting in deformations of the reservoir rock, as well as changes of the porosity and permeability. Therefore, this is a coupled problem where the fluid flow in the reservoir rock and the rock geomechanical and geochemical behavior are correlated (Guimarães et al., 2009).

Mineral dissolution has been used to explain artificial and natural chemical weathering of rocks as a result of geological or engineering processes such as stimulation of petroleum reservoirs, mining degradation, geological sequestration of carbon dioxide, diagenesis, and dissolution/formation of hydrates (Chen et al., 2009). Some consequences of the mineral dissolution are changes of porosity and permeability, chemically induced reservoir compaction and decreasing of shear strength. In the area of Reservoir Geomechanics, the term "reservoir compaction" is referred to all mechanisms which result in decreasing of rock volume due to pore collapse.

Cecilia Lins, PhD., Centro de Ciências e Tecnologia, Universidade Católica de Pernambuco, Recife, PE, Brazil. e-mail: cecilia.lins@gmail.com.

Nayra Silva, PhD., Centro de Tecnologia, Universidade Federal de Alagoas, Maceió, AL, Brazil. e-mail: nayvicente@gmail.com.

Leonardo Guimarães, PhD., Departamento de Engenharia Civil, Universidade Federal de Pernambuco, Recife, PE, Brazil. e-mail: leojnguimaraes@ gmail.com.

Analice Lima, PhD., Departamento de Engenharia Civil, Universidade Federal de Pernambuco, Recife, PE, Brazil. e-mail: analicelima@ hotmail.com.

Igor Gomes, PhD., Departamento de Engenharia Civil, Universidade Federal de Pernambuco, Recife, PE, Brazil. e-mail: gomes@ufpe.br.

Invited Article, no discussion. 
So, in the case of the chemically induced reservoir compaction, it is observed the decreasing of rock volume under constant mechanical boundary conditions when a reactive fluid is injected into the geological formation. From the pore scale point of view, the injection of aggressive fluids causes cement dissolution, weakening of bounds between inert minerals and finally pore collapse. It is observed also a decreasing of shear strength and stiffness. This phenomenon is known as water-weakening of the rock (Korsnes et al., 2008; Silva, 2012).

Nowadays, the analysis of geomechanical effects on deformable soils and rocks induced by chemical dissolution is an open field. The knowledge of the coefficient of earth pressure at rest $\left(K_{0}\right)$ is a key parameter for many subsurface applications of Civil, Petroleum and Mining Engineering. For instance, $K_{0}$ is fundamental to verify the stability of well perforations and underground excavations such as tunnels and galleries. Its value reflects the soil characteristics and stress history.

Despite its importance on the evolution of $K_{0}$ during the formation history of the rock, such as changes of chemical and mechanical conditions, is very limited (Shin \& Santamarina, 2009). At laboratory scale, it is also not easy to determine $K_{0}$ when the soil or rock is simultaneously loaded and exposed to reactive fluids in the attempt to simulate diagenetic or weathering processes. In this area, authors such as Shin and Santamarina (2009) and Castellanza and Nova (2004) have given some insights into this complex behavior of cemented soils and rocks. They developed modified oedometer cells to evaluate changes of horizontal stress caused by mineral dissolution. Performing tests using these modified apparatus, they were able to determine the complete stress path during rock exposure to a reactive fluid at constant vertical stress.

This paper describes tests performed with an oedometer cell similar to those proposed by Castellanza \& Nova (2004) and Shin \& Santamarina (2009) using an artificial soil proposed by Shin \& Santamarina (2009), composed of glass beads as the inert mineral and sodium chlorite as the cement at different concentrations (12\% and 20\%). The reactive fluid is distilled water, which will dissolve the sodium chlorite.

Based on the framework proposed by Gens \& Nova (1993), Castellanza \& Nova (2004) also proposed a constitutive model able to reproduce the stress path observed in carbonatic soft rocks subjected to acid injection. In Gens \& Nova (1993), the basic conceptual requirements for constitutive models for bonded soils and weak rocks are discussed within the framework of hardening plasticity. A reference model for unbonded material is used as a start point and it is modified according to the magnitude of bonding. Finally, material degradation is simulated by a reduction of degree of bonding caused by mechanical and chemical actions. The model incorporates bonding to the material behavior in a similar way of suction, as both confer an additional strength and stiffness to the material.

In the elasto-plastic model proposed by Castellanza \& Nova (2004), the reference model for the unbonded material is based on the Critical State Theory and a new state variable to represent bonding is proposed. This new variable affects the shear strength (cohesion) and pre-consolidation stress of the material and its evolution is a result of imposed mechanical and chemical loads. The model is also able to simulate irreversible (plastic) strain due to material degradation, by modifying the hardening law which relates evolution of the pre-consolidation stress and volumetric plastic strain. It is proposed in this paper a modification of Castellanza \& Nova (2004) model to include deformations and changes of stresses due to solid mass loss in the elastic part of the model.

The model was implemented in a general purpose finite element code (Olivella et al., 1994 and Guimarães et al., 2007) capable of performing coupled thermo-hydromechanical and chemical (THMC) analysis of engineering problems. The model was implemented as an extension of the Barcelona Basic Model (BBM) for unsaturated soils, now incorporating bonding effects. The chemical variable selected to affect the bonding of the material is the concentration of the cement, represented in the chemical model (reactive transport problem) as a precipitated mineral. Experimental evidence is still necessary to validate the model when both effects of no saturation and chemical changes take place simultaneously.

In the validation exercise presented here, only the chemical part of the model is validated for a previously saturated soil. Coupled hydro-mechanical and chemical (HMC) analysis of the modified oedometer tests was performed in order to reproduce the most significant aspects of the observed behavior of the sample subjected to simultaneous mechanical and chemical loads. The experimental procedure was carried out using a modified oedometer cell with horizontal stress measurements and synthetic samples in order to simulate simultaneous cement dissolution, stress changes and sample deformation. The samples were loaded at a constant vertical stress and exposed to a reactive fluid which dissolved the cementation of the artificial soil. In this analysis, the mass balance equations for water and all chemical species (flow and reactive transport problems) and the balance equation for momentum (mechanical problem) are solved together in a fully coupled way according to Guimarães et al. (2007).

\section{Experimental Programme}

\subsection{Experimental setup - Soft oedometer cell}

Figure 1 shows the scheme of the modified soft oedometer cell used to perform the tests. The equipment was developed and instrumented based on specifications outlined by Castellanza \& Nova (2004) and Shin \& Santamarina 


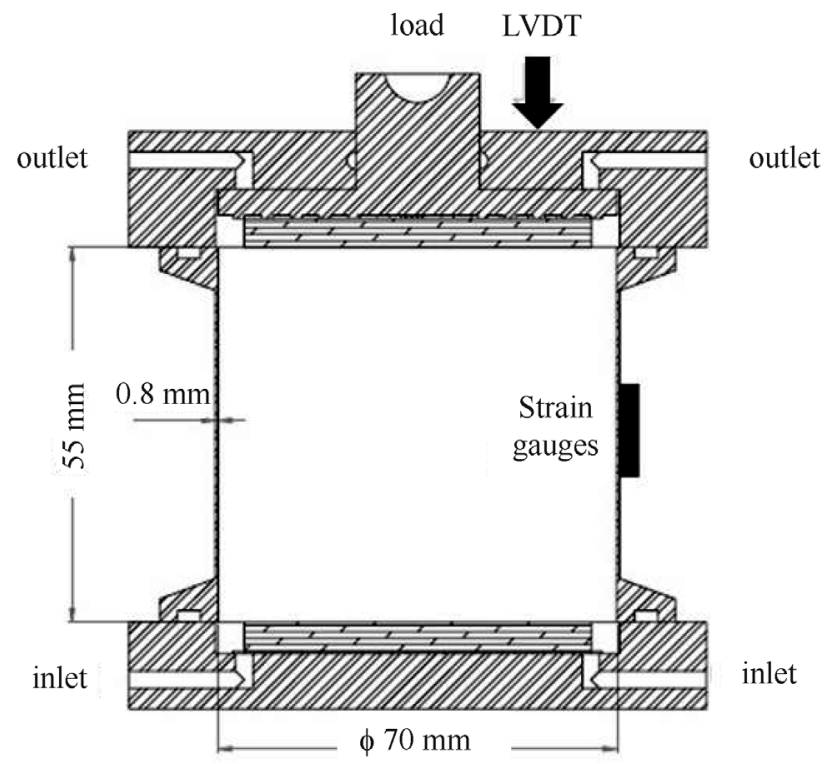

Scale 1:0.7

Figure 1 - Scheme of modified soft oedometer cell.

(2009), specifically designed to measure the horizontal stress.

This cell is composed by an aluminum-bronze alloy using a ring with $70 \mathrm{~mm}$ in diameter, $55 \mathrm{~mm}$ in height and $0.8 \mathrm{~mm}$ thickness. A thin ring is used allowing very small horizontal strain (quasi-oedometric conditions) measured by strain gages attached to the ring wall. Strain gages are calibrated in order to directly correlate wall deformation and horizontal stress. The four strain gauges installed are used to reach two different objectives: two of them to measure horizontal stress and the other two to correct temperature influence.

The sample is placed inside the ring between two porous stones and the whole set is fixed by top and bottom caps. The inlet and outlet water valves are connected in the caps. The vertical displacements are measured using Linear Variable Differential Transformers (LVDT). Before performing the tests, the different transducers were carefully calibrated. The vertical displacements and horizontal stress measurements during the tests were stored using a data acquisition program specifically designed for this equipment.

\subsection{Test protocol}

The experimental tests were carried out using synthetic samples proposed by Shin \& Santamarina (2009). The samples consist of a mixture of glass beads and sodium chloride $(\mathrm{NaCl})$ with diameter of $2 \mathrm{~mm}$. The synthetic samples were used in order to represent and understand the chemical phenomena during dissolution processes and the impact on hydraulic and mechanical properties on natural porous materials, with the aim to simulate the chemical effects on geological formations subjected to fluid injection, such as rock reservoirs. The test protocol was carried out in two stages: (1) to obtain the yield stress and (2) to obtain the time evolution of volumetric strain and horizontal stress during chemical dissolution.

Initially, glass beads and $\mathrm{NaCl}$ were mixed under a salt-saturated brine to prevent $\mathrm{NaCl}$ dissolution and placed in the oedometer cell. In the first protocol tests, the samples were loaded/unloaded (up to $150 \mathrm{kPa}$ ) in order to obtain the yield stress. In the second protocol tests, an initial vertical stress of $5 \mathrm{kPa}$ was applied to ensure the contact between the sample and the loading system, after that the vertical stress was increased to $25 \mathrm{kPa}$. A constant backpressure of $8 \mathrm{kPa}$ was applied using distilled water with the aim to dissolve the $\mathrm{NaCl}$ of the sample. During this stage, the top valve was maintained open and the water permeability and electrical conductivity were measured. The tests ended when the vertical displacement reading was constant and the electric conductivity reached values close to $3 \mathrm{mS} / \mathrm{cm}$, indicating the complete dissolution of $\mathrm{NaCl}$.

Several tests were carried out at controlled temperature room at $22{ }^{\circ} \mathrm{C}$ and this experimental protocol was repeated for different concentrations of $\mathrm{NaCl}(12 \%$ and $20 \%$ in weight).

\subsection{Experimental results}

Figure 2a shows the step-loading/unloading curves in terms of void ratio $(e)$ and vertical stress $\left(\sigma_{v}\right)$ and Fig. $2 \mathrm{~b}$ shows the same curve in terms of specific volume $(v)$ and mean stress $(p)$ for $\mathrm{NaCl}$ concentration of $12 \%$. According to this result, the initial void ratio is $e_{0}=0.43$ and the preconsolidation stress is approximately $=20 \mathrm{kPa}$. Values for compression index $\left(C_{c}\right)$ of 0.017 and recompression in$\operatorname{dex}\left(C_{r}\right)$ of 0.003 were determined from the curves in Fig. 2a.

Figures 3a shows the time evolution of volumetric strain for loading and $\mathrm{NaCl}$ dissolution stages for different $\mathrm{NaCl}$ concentrations. During step-loading and $\mathrm{NaCl}$ dissolution stages, the samples were consolidated and the volumetric strain decreases to 8 and $17 \%$ for $\mathrm{NaCl}$ concentrations of 12 and $20 \%$, respectively. So, samples with higher $\mathrm{NaCl}$ concentrations achieved larger values of volumetric strains due to grain mass loss during the $\mathrm{NaCl}$ dissolution. The same behavior was observed in the tests performed by Shin \& Santamarina (2009), where the volumetric strains obtained were about of 2,4 , and $6 \%$ for $\mathrm{NaCl}$ concentrations of 5,10 and $15 \%$, respectively.

Figures $3 \mathrm{~b}$ presents the time evolution of horizontal effective stress at different $\mathrm{NaCl}$ concentrations. During the step-loading stage, the horizontal effective stress increases to about $26 \mathrm{kPa}$ for different $\mathrm{NaCl}$ concentrations. During the $\mathrm{NaCl}$ dissolution, at first, a pronounced horizontal effective stress drop was observed due to the grain mass loss. After that, a rise in the horizontal effective stress is observed due to rearrangement of internal granular structure (development of plastic strains). Increasing of horizontal 

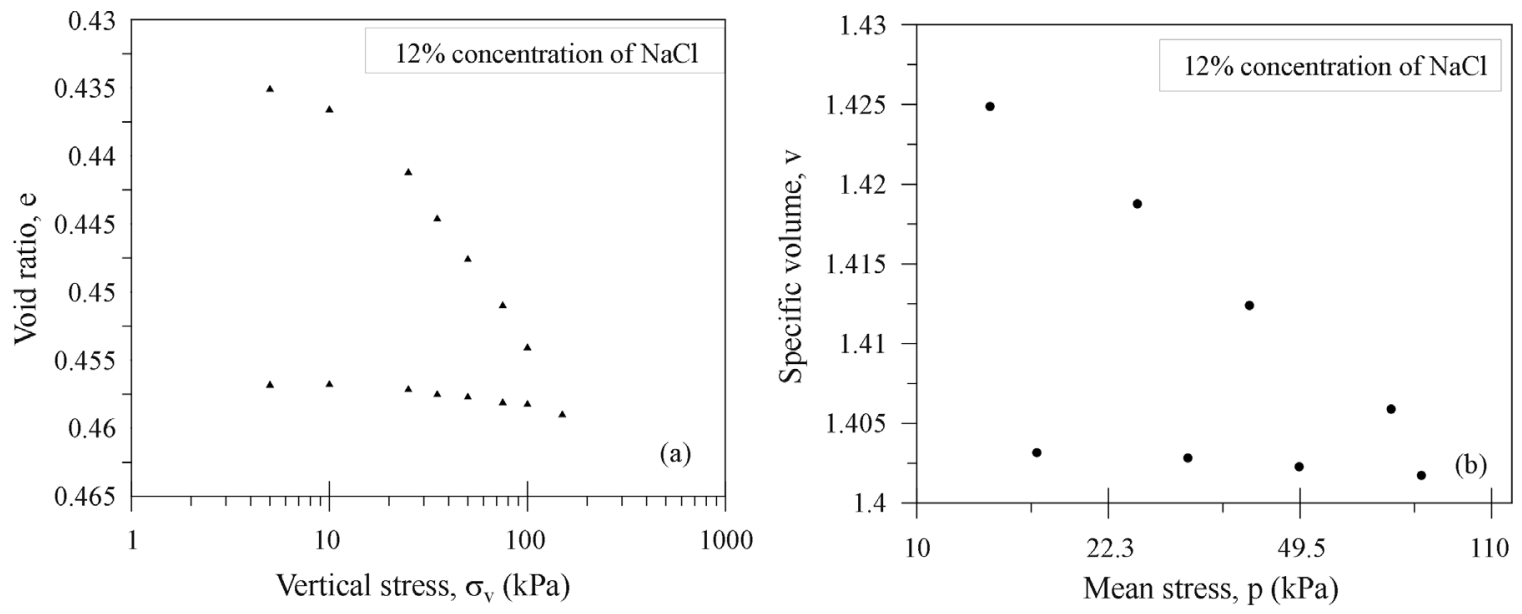

Figure 2 - Step-loading/unloading paths with $12 \%$ of $\mathrm{NaCl}$ concentration in terms of (a) void ratio vs. vertical stress and (b) specific volume and mean stress.
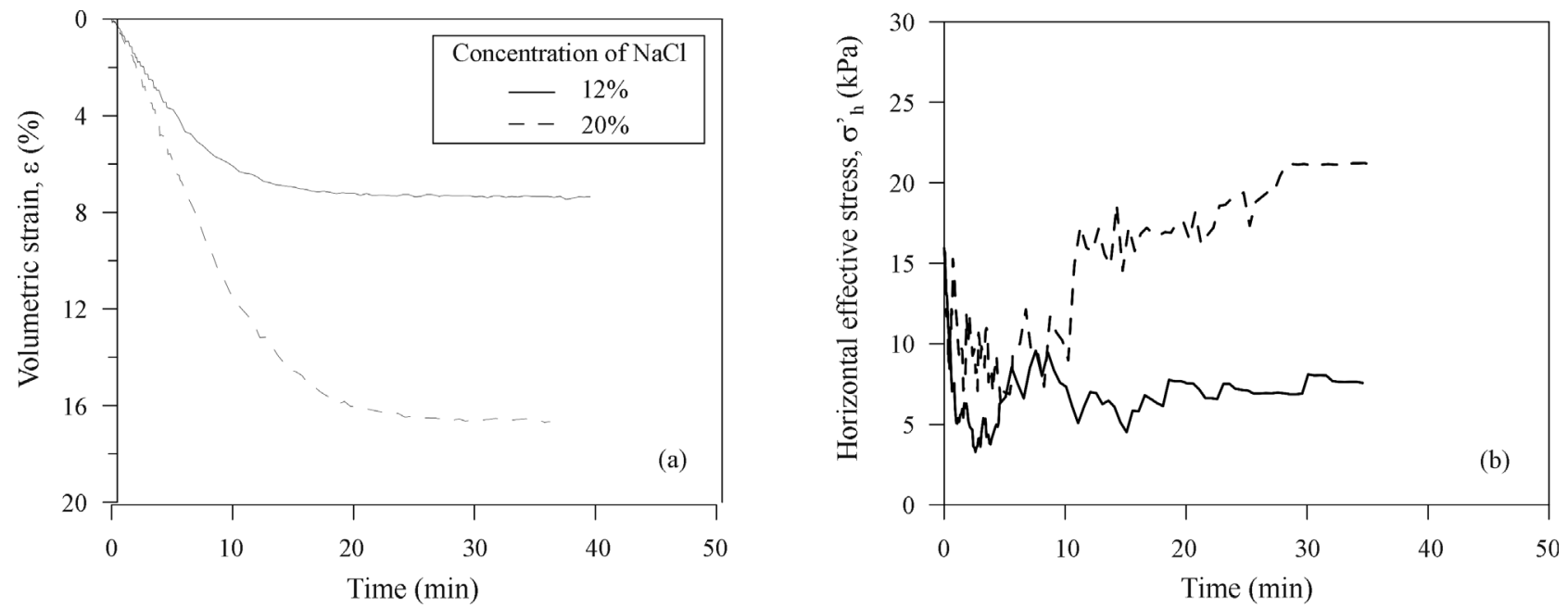

Figure 3 - Time evolution of volumetric strain and horizontal effective stress for $\mathrm{NaCl}$, concentration of $12 \%$ and $20 \%$.

effective stress can be only explained by development of compressive horizontal elastic strain. At oedometric conditions (sample is not allowed to deform horizontally) this is also directly related to development of expansive horizontal plastic strain, as it will be shown in the next sections. However, Pereira \& Fredlund (2002) used the concept of stress-induced anisotropy to interpreted the changes in horizontal stresses during collapse.

Increasing of horizontal effective stress was more strongly observed in the tests with the $\mathrm{NaCl}$ concentration of $20 \%$. At the end of the test its value was lower than the initial horizontal effective stress observed for samples with $\mathrm{NaCl}$ concentrations of $12 \%$. But for the sample with $\mathrm{NaCl}$ concentration of $20 \%$, the final horizontal effective stress is higher than the initial value.

Therefore, the results showed in this paper had a similar behavior with the results presented by Shin \& Santamarina (2009). Initially, when water injection begins, hori- zontal stress decreases due to the loss of sodium chlorite mass. After some minutes of fluid injection, horizontal stress begins to increase due to rearrangement of the internal granular structure. During the entire test, vertical stress is maintained constant and sample volume decreases (compressive vertical strains were observed and horizontal strains were prevented).

Figure 4 presents the time evolution of electrical conductivity during $\mathrm{NaCl}$ dissolution for different $\mathrm{NaCl}$ concentrations of 12 and $20 \%$. In this figure, a reduction in the electrical conductivity caused by the $\mathrm{NaCl}$ dissolution was observed. Initially, the electrical conductivity decreases faster for all $\mathrm{NaCl}$ concentrations. However, a faster reduction of electrical conductivity in samples with a lower $\mathrm{NaCl}$ concentration was also observed, due to the lower amount of $\mathrm{NaCl}$ in the sample. Basically, the dissolution test ended after about 40 min for $\mathrm{NaCl}$ concentration of 12 and $20 \%$, when the electrical conductivity reaches values below $3 \mathrm{mS} / \mathrm{cm}$. 


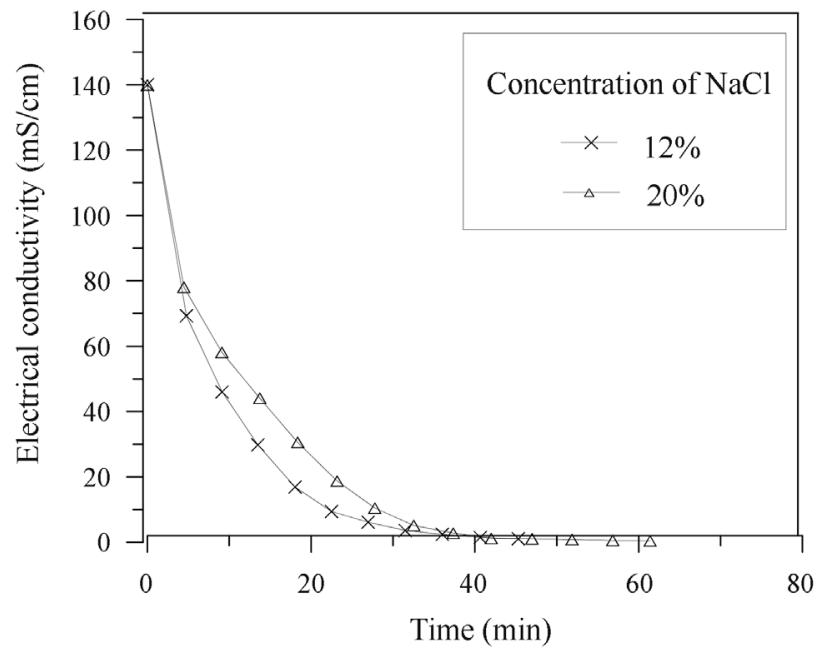

Figure 4 - Time evolution of electrical conductivity for $\mathrm{NaCl}$, concentrations of 12 and $20 \%$.

The average permeability obtained during dissolution tests for different concentrations was about $2.6 \times 10^{-5} \mathrm{~m} / \mathrm{s}$. Significant variation of the permeability between the different $\mathrm{NaCl}$ concentrations was not observed.

\section{Mathematical Formulation}

In this section the constitutive model proposed by Castellanza \& Nova (2004) for bonded materials is described and a modification to include strain and stress changes due to grain mass loss is proposed. The constitutive model was implemented as an extension of the Barcelona Basic Model (BBM) (Alonso et al., 1990) for unsaturated soils, including the cement concentration as a new chemical state variable for the mechanical behavior.

\subsection{Constitutive model for bonded materials}

The BBM model considers two independent stress variables to describe the behavior of unsaturated soils. They are the net stress $\left(\sigma^{\prime}=\sigma-u_{a} I\right)$ and suction $\left(s=u_{a}-u_{w}\right)$, obtained as a function of total stress and air and water pressures $\left(u_{a}, u_{w}\right)$. It consists in a hardening elastoplastic model with a yield surface defined as function of net mean stress $p$, deviatoric stress $q$ and suction $s$ in a three-dimensional space (Alonso et al., 1990).

In order to consider the effect of artificial or natural weathering a modification of BBM is adopted, based on the model proposed by Castellanza \& Nova (2004). In this case, the yield function also depends on history variables related to plastic strain and bonding. The yield surface is expressed as:

$$
\begin{aligned}
& f=f\left(p, q, s, \varepsilon_{v}^{p}, X_{d}\right)= \\
& q^{2}-M^{2}\left(p+p_{s}\right)\left(p_{0}-p\right)=0
\end{aligned}
$$

with

$$
\begin{aligned}
& p=\sigma_{m}-\max \left(p_{a}, p_{l}\right) ; \quad \sigma_{m}=\frac{\sigma_{1}+\sigma_{2}+\sigma_{3}}{3} \\
& q=\sigma_{1}-\sigma_{3}
\end{aligned}
$$

where $\sigma_{1}, \sigma_{2}$ and $\sigma_{3}$ are the total principal stress, $\sigma_{m}$ is the mean stress, is the plastic volumetric strain, $M$ is the slope of the critical state and, $p_{s}$ is related to shear strength material as function of the suction and chemical weathering. $X_{d}$ is a scalar index that gives the degree of chemical degradation. Equation 1 gives the shape of the elastic domain (Fig. 5).

In Fig. 5, the two yield surfaces represent the soil under bonded and unsaturated conditions $\left(F_{B}\right)$ and the soil under unbonded (degraded) and saturated conditions $\left(F_{A}\right)$. Herein, the Modified Cam-Clay model was adopted as the reference model to reproduce the unbonded saturated soil behavior. In the proposed model, $p_{0}$ is the apparent isotropic preconsolidation stress for the unsaturated and bonded conditions, which is related to suction, saturated unbonded preconsolidation stress, and the chemical weathering expressed by addition of the bonding variable $p_{m}$. The relationship is expressed as:

$$
p_{0}=p\left(\frac{p_{0}^{*}}{p^{c}}\right)^{\frac{\lambda(0)-\kappa}{\lambda(s)-\kappa}}+p_{m}
$$

where $p^{c}$ is a reference stress, $\kappa$ is the elastic stiffness parameter, $\lambda(0)$ is the slope of the virgin consolidation line on saturated and isotropic conditions, $\lambda(s)$ is the slope of the virgin consolidation line for isotropic loading at constant suction.

The variable $\lambda(s)$ is expressed as:

$$
\lambda(s)=\lambda(0)\left[(1-r) \exp \left(-\beta_{s} s\right)+r\right]
$$

where $r$ is the limiting value of soil stiffness for high suction and $\beta_{s}$ controls the rate stiffness increase with suction.

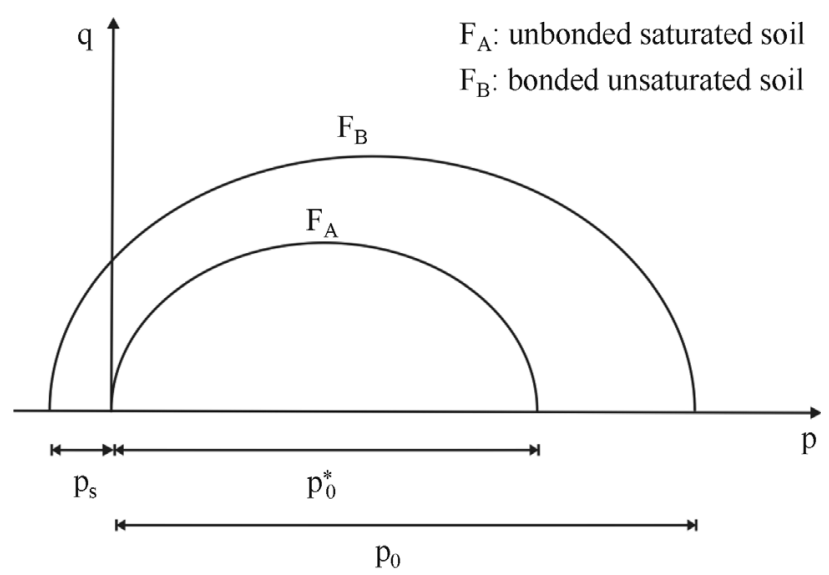

Figure 5 - Yield surfaces for bonded and unbonded soils in $p-q$ plane. 
In Eq. 4 , the term $p\left(\frac{p_{0}^{*}}{p^{c}}\right)^{\frac{\lambda(0)-\kappa}{\lambda(s)-\kappa}}$ is related to unsaturated condition of porous media (suction) to the apparent preconsolidation stress (Alonso et al., 1990). The variable $p_{m}$, which is related to bonding, is given by:

$$
p_{m}=\beta p_{t}
$$

where $\beta$ is a constant and $p_{t}$ is an internal variable which controls the bond strength through chemical weathering.

The other important internal variable $p_{s}$ is related to the increasing of shear strength (cohesion) of the material due to its unsaturation or bonding. It is defined by suctionand chemical weathering variable $p_{t}$ :

$$
p_{s}=k_{s}+p_{t}
$$

where $k$ describes the increase of the apparent cohesion with suction $s$.

The variables $p_{s}, p_{0}^{*}, p_{m}$ and $p_{t}$ govern the size of the elastic domain. The last two $\left(p_{m}\right.$ and $\left.p_{t}\right)$ are related to bonding and they are affected by both plastic degradation (induced by stress changes) and chemical weathering (Castellanza \& Nova, 2004).

The variable $p_{t}$ changes due to mechanical and chemical actions and can be expressed as:

$$
\dot{p}_{t}=p_{t}\left[-\rho_{t}\left|\dot{\varepsilon}_{v}^{p}\right|+\frac{\dot{Y}}{Y\left(X_{d}\right)}\right]
$$

where $\rho_{t}$ controls the rate of mechanical degradation, and $Y\left(X_{d}\right)$ is a function which controls the decrease of $p_{t}$ with the degree of chemical degradation $X_{d}$.

$$
Y\left(X_{d}\right)=\left(1-X_{d}\right)^{2}
$$

When $X_{d}$ increases mineral precipitation takes place and when it decreases the result is mineral dissolution. As proposed by Castellanza \& Nova (2004), $X_{d}$ ranges from 0 (bonded material) to 1 (totally unbonded material). $X_{d}$ is directly related to the cement concentration and represents the degree of bonding of the material. Cement concentration is an important variable for this problem as it gives the degree of degradation (weathering) of the bonded soil. In present paper it is proposed a linear correlation between the degree of chemical degradation $X_{d}$ and the cement mineral concentration $C$, given by:

$$
X_{d}=\frac{C_{0}-C}{C_{0}}
$$

where $C_{0}$ is the initial mineral concentration. The variable $C$ is the mineral concentration for a time $t$ of the degradation process and comes from the reactive transport problem, solved simultaneously with the fluid flow and mechanical problems.

The hardening/softening law that relates changes of to volumetric plastic strain is given by the same law for
BBM and Modified Cam-Clay model, based on the Critical State Theory:

$$
\frac{d p_{0}^{*}}{p_{0}^{*}}=d \varepsilon_{v}^{p} \frac{v}{\lambda(0)-\kappa}
$$

where $v=1+e$ is the specific volume and $e$ is the void ratio.

Another important element of this formulation is the model for the elastic behavior of the material. Here, the elastic strains is related to changes in stress, suction and chemical degradation as follows:

$$
d \varepsilon^{e}=\frac{\kappa}{\nu} \frac{d p}{p}+\frac{1}{3 G} d q+\frac{\kappa_{s}}{\nu} \frac{d s}{\left(s+p_{a t m}\right)}+\frac{\alpha \kappa}{\nu} \frac{d X_{d}}{p}
$$

where $G$ is the shear modulus, $\kappa_{s}$ is the elastic stiffness related to suction, $p_{a t m}$ is the atmospheric pressure and $\alpha$ is a chemo-elastic parameter. In the present paper, a term related to changes of $X_{d}$ was introduced in Eq. 12 with the objective to reproduce soil contraction due to mineral mass loss.

\subsection{Model validation}

A preliminary validation of the proposed model was performed using the results from the experimental program presented in Section 2. The simulations of the oedometer tests were performed with $\mathrm{NaCl}$ concentrations of 12 and $20 \%$, mixed with the glass beads. In order to validate the constitutive model a uniform mineral dissolution was imposed along the sample. In the numerical simulations a one-dimensional finite element mesh of 20 elements was adopted. The boundary conditions for the mechanical problem are: applied load at the top of the sample and no displacement is allowed at the bottom. These geometry and boundary conditions presume that the cell is rigid and the friction between the cell and the sample is negligible.

The material parameters used in the simulations are presented in Table 1. Typical values for sands (granular soils) were adopted for Poisson's ratio ( $v)$, friction angle $(\phi)$ and slope of the critical state line $(\mathrm{M})$. The values of

Table 1 - Material parameters for HMQ analysis.

\begin{tabular}{lc}
\hline Parameters & Sample \\
\hline Slope of the unloading-reloading line, $\kappa$ & $1.4 \mathrm{e}^{-3}$ \\
Slope of virgin consolidation line, $\lambda$ & $7.2 \mathrm{e}^{-3}$ \\
Preconsolidation stress & $20 \mathrm{kPa}$ \\
Poisson's ratio, $v$ & 0.40 \\
Permeability, $k$ & $2.6 \times 10^{-5} \mathrm{~m} / \mathrm{s}$ \\
Friction angle, $\phi$ & $30^{\circ}$ \\
Slope of the critical state line, $M$ & 1.00 \\
Internal variable related to the strength of bonds, $p_{t}$ & 0.010 \\
Harding parameter of mechanical degradation, $\rho_{t}$ & 10.0 \\
\hline
\end{tabular}


preconsolidation stress, slope of the unloading-reloading line $(\kappa)$, slope of virgin consolidation line $(\lambda)$ and the water permeability $(k)$ were calibrated from the tests results.

Figures $6 \mathrm{a}$ and $7 \mathrm{a}$ show the time evolution of volumetric strain of experimental and predicted results for different $\mathrm{NaCl}$ concentrations of 12 and $20 \%$, respectively. Figures $6 \mathrm{~b}$ and $7 \mathrm{~b}$ display the corresponding time evolutions of horizontal stress (experimental and predicted results). In these figures, it can be seen that the simulated and experimental results showed a good agreement in both volumetric strain and horizontal stress evolutions for 12 and $20 \%$ of $\mathrm{NaCl}$ concentrations. During the $\mathrm{NaCl}$ dissolution, it can be observed that the numerical results could represent the pronounced horizontal effective stress drop as well as decreases of volumetric strain due to a grain mass loss. The model was also able to represent a rise in the horizontal stress due to solid matrix rearrangement, as observed in the
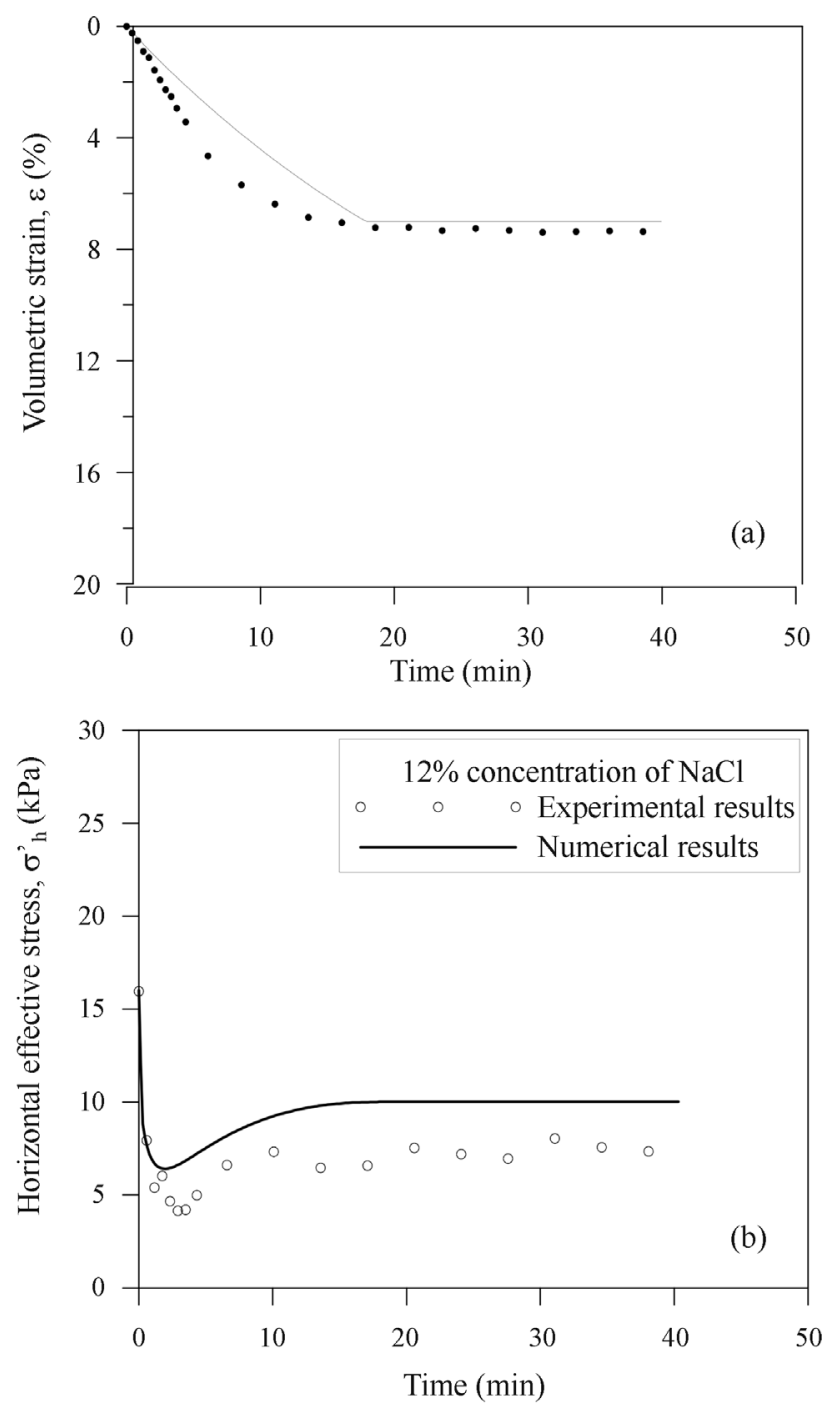

Figure 6 - Time evolution of volumetric strain and horizontal effective stress of experimental and numerical results for $\mathrm{NaCl}$ concentration of $12 \%$. experimental results. However, it can be seen in Fig. 7b ( $\mathrm{NaCl}$ concentration of $20 \%$ ) that the model does not fit perfectly the experimental data, where higher values of horizontal stress were measured. Improvements of the numerical model are necessary in order to achieve higher values of horizontal stress, which are related to the plastic behaviour of the material.

A good representation of the volumetric strain was obtained for the values adopted for the chemo-elastic coefficient $\alpha$ (Eq. 12). The calibration of model for the two artificial soils gave the values of 0.07 and 0.165 for $\mathrm{NaCl}$ concentrations of 12 and $20 \%$, respectively.

Figure $8 \mathrm{a}$ and $8 \mathrm{~b}$ show the evolution of hardening variables for $\mathrm{NaCl}$ concentrations of 12 and $20 \%$, respectively. In these figures, it can be observed that the samples ( $\mathrm{NaCl}$ concentrations of 12 and 20\%) show similar behavior with respect to hardening variables during mineral dis-
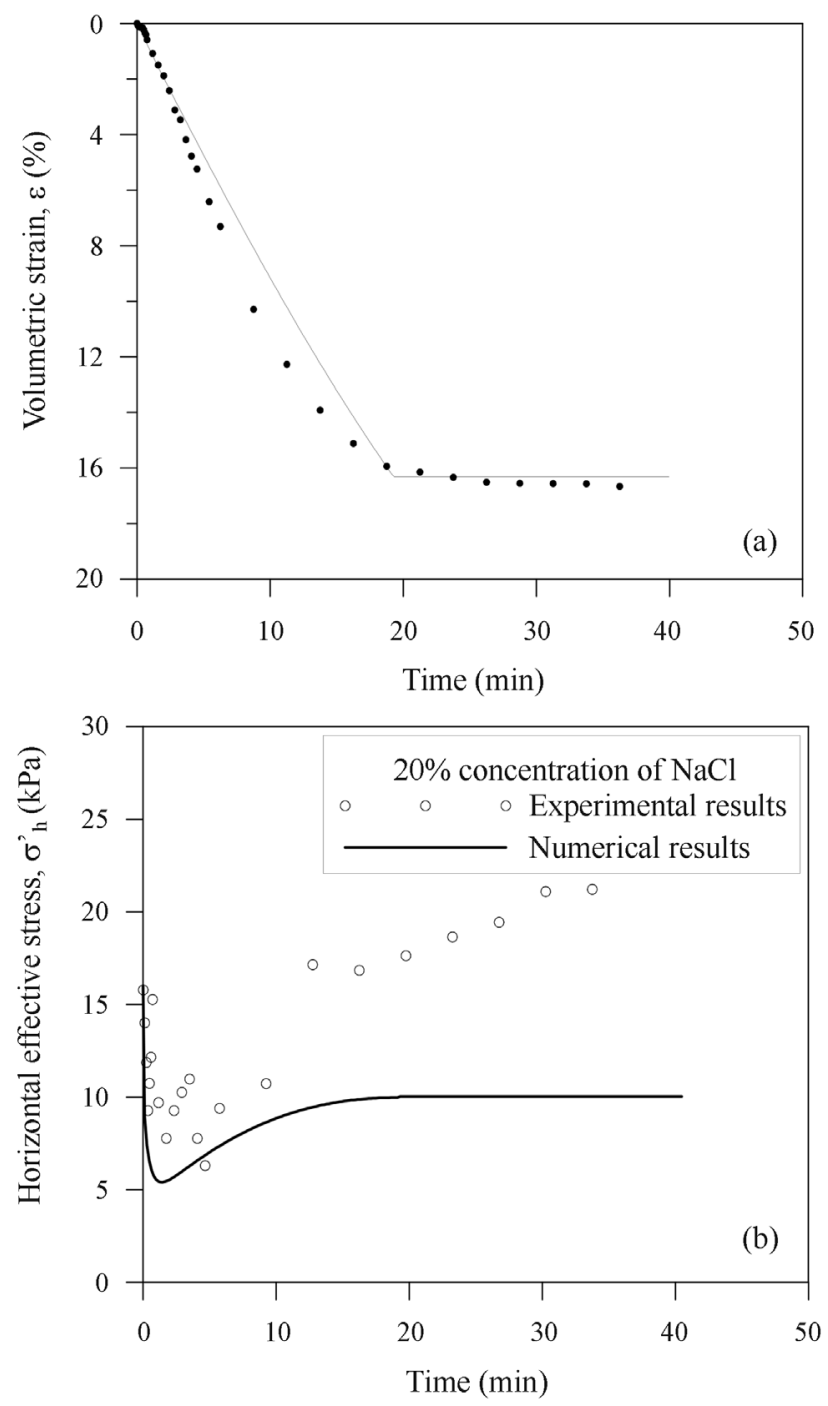

Figure 7 - Time evolution of volumetric strain and horizontal effective stress of experimental and numerical results for $\mathrm{NaCl}$ concentration of $20 \%$. 

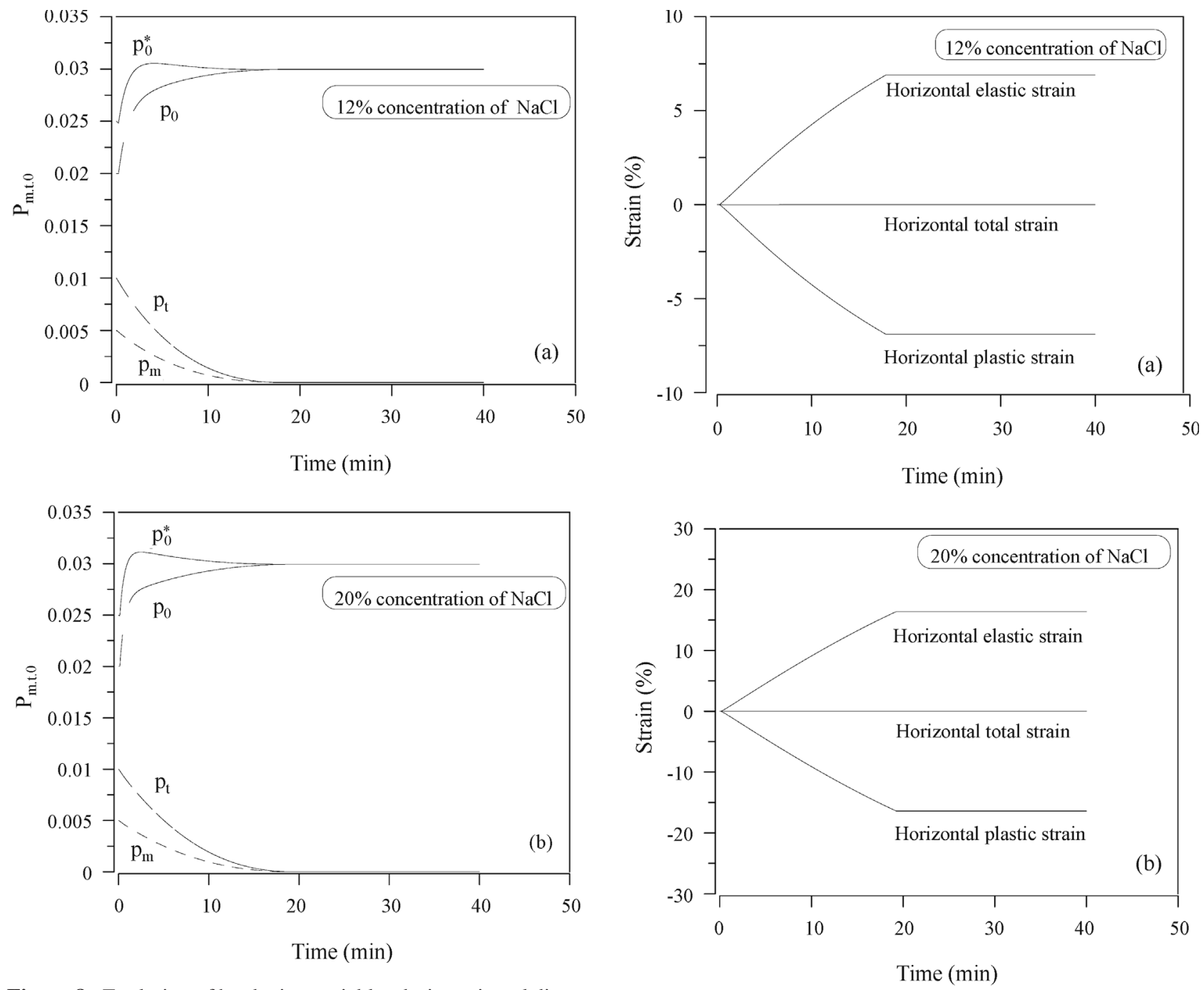

Figure 8 - Evolution of hardening variables during mineral dissolution for $\mathrm{NaCl}$ concentrations of 12 and $20 \%$.

solution. As expected, the parameters $p_{m}$ and $p_{t}$ decrease when chemical degradation takes place. As the artificial soil is close to the normally consolidated state, a hardening of the material is also observed, where increases as a result of the development of compressive volumetric plastic strain (as described by Eq. 11).

Figures $9 \mathrm{a}$ and $9 \mathrm{~b}$ show the evolution of horizontal strains during mineral dissolution. In both tests it is observed the evolution of negative horizontal plastic strain, which (swelling) is related to irreversible solid matrix rearrangement. As total horizontal strain is not allowed in the oedometer test, positive horizontal elastic strain (compression) takes place to maintain the equilibrium, which results in a more compressive state of stress as the horizontal stress increases. The value of the horizontal plastic strain is equal in module to the values of horizontal elastic strain, so, .

Figure 9 - Evolution of elastic and plastic horizontal strains during mineral dissolution for $\mathrm{NaCl}$ concentrations of 12 and $20 \%$.

\section{Conclusions}

A series of tests along step-loading/unloading and $\mathrm{NaCl}$ dissolution paths were performed to study the geomechanical effects caused in the porous medium during mineral dissolution. The tests were carried out in a fullyinstrumented oedometer cell with LVDT and strain gauges, specially constructed to measure horizontal stress.

Results of a comprehensive experimental programme on synthetic samples (mixture of glass beads and $\mathrm{NaCl}$ ) at different $\mathrm{NaCl}$ concentrations were presented and discussed in terms of the simultaneous measurements of volumetric strains and horizontal stresses during the dissolution tests.

During $\mathrm{NaCl}$ dissolution stage, sample volume decreases decreases. Samples with higher $\mathrm{NaCl}$ concentrations achieved larger values of volumetric strains. A pronounced horizontal effective stress drop was observed and 
then it starts to increase. This behavior was observed for the different $\mathrm{NaCl}$ concentrations but it was more pronounced in the tests with the $\mathrm{NaCl}$ concentration of $20 \%$. The $K_{0}$ values were affected by the mineral dissolution process, as a result of chemically induced pore collapse and solid matrix rearrangement.

Encouraging agreement has been found concerning the validation of the proposed formulation. During the $\mathrm{NaCl}$ dissolution, numerical simulation could represent the pronounced drop of sample volume. The model was also able to reproduce the changes of horizontal stress observed in the experiments. For the sample with higher $\mathrm{NaCl}$ concentration $(20 \%)$, numerical results of horizontal stress did not reach the experimental values, but they were in qualitative agreement.

\section{Acknowledgments}

The authors acknowledge the financial support from PETROBRAS, CNPq (Brazilian National Research Consul) and Foundation CMG (Chair on Reservoir Simulation at UFPE).

\section{References}

Alonso et al. (1990). A constitutive model for partially saturated soils. Geotechnique, 40(3):405-430.

Alonso, E.E. \& Gens, A. (1993). On the mechanical behavior of arid soils. Proc. 1st Internacional Symposium on Engineering Characteristics of Arid Soils, London, England, v. 1, pp. 173-205.

Castellanza, R. \& Nova, R. (2004). Oedometric tests on artificially weathered carbonatic soft rocks. J. Geotech. \& Geoenv. Eng., 130(7):728-739.

Chen et al. (2009). Effects of mechanical dispersion on the morphological evolution of a chemical dissolution front in a fluid-saturated porous medium. J. of Hydrology, 373(1-2):96-102.

Costa et al. (2008). Numerical modelling of hydro-mechanical behaviour of collapsible soils. Communications in Numerical Methods in Engineering, 24(12):1839-1852.

Fogler, H.S. \& Rege, S.D. (1989). Competition among flow, dissolution, and precipitation in porous media. AIChE J., 35(7):1117-1185.

Gens, A. (2010). Soil-environment interactions in geotechnical engineering. Geotechnique, 60(1):3-74.

Gens, A. \& Nova, R. (1993). Conceptual bases for a constitutive model for bonded soils and weak rocks. Proc. International Symposium On Geomechanical Engineering of Hard Soils and Soft Rocks, Athens, v. 1, pp. 485-494.
Gouze et al. (2001). Computing permeability change in sedimentary reservoirs including clays: application to the Bray fault zone (Paris Basin). B. Soc. Geol., 172(4):427-436.

Guimarães et al. (2006). THM and reactive transport analysis of expansive clay barrier in radioactive waste isolation. Communications in Numerical Methods in Engineering, 22(8):849-859.

Guimarães et al. (2007). Coupled thermo-hydro mechanical and chemical analysis of expansive clay subjected to heating and hydration. Transport in Porous Media, 66(3):341-372.

Guimarães et al. (2009). Influence of mechanical constitutive model on the coupled hydro-geomechanical analysis of fault reactivation. In: Reservoir Simulation Symposium - Society of Petroleum Engineers SPE, The Woodlands, Texas, SPE-119168-PP(CD-ROM).

Guimarães et al. (2013). A chemo-mechanical constitutive model accounting for cation exchange in expansive clays. Geotechnique, 63(3):221-234.

Korsnes et al. (2008). Enhanced chemical weakening of chalk due to injection of $\mathrm{CO}_{2}$ enriched water. In: International Symposium of The Society of Core Analysts, Abu Dhabi, October 29-November 2 2008, v.1, pp. 1-12.

Lins et al. (2012). Analysis of the carbon dioxide $\left(\mathrm{CO}_{2}\right)$ injection in carbonate rocks. Cientec., 4(2):84-91.

Melo et al. (2013). Análise numérico-experimental de rochas carbonáticas sintéticas submetidas á injeção de um fluido reativo. In: : $2{ }^{\circ}$ Congresso Brasileiro de $\mathrm{CO} 2$ na Indústria de Petróleo, Gás e Biocombustíveis. (CDROM).

Navarro et al. (2010). A constitutive model for porous rock including effects of bond strength degradation and partial saturation. International Journal of Rock Mechanics \& Mining Sciences, 47(8):1330-1338.

Olivella et al. (1994). Nonisothermal multiphase flow of brine and gas through saline media. Transport in Porous Media, 15(3):271-293.

Pereira, J.H.F. \& Fredlund, D.G. (2000). Volume change behavior of collapsible compacted gneiss soil. J. Geotech. Geoenviron. Eng., 128(2):184-185.

Shin, H. \& Santamarina, J.C. (2009). Mineral dissolution and the evolution of $K_{0}$. J. of Geotech. \& Geoenv. Eng., 135(8):1141-1147.

Silva, N.V.S. (2012). Modeling the Phenomenon of Capillary and Chemical Compaction in Petroleum Reservoirs. PhD Dissertation, Department of Civil Engineering, Federal University of Pernambuco, 136 p.

Uchaipichat, A. (2011). An elasto-plastic model for cemented soils under unsaturated condition. European Journal of Scientific Research, 60(2):231-236. 